\title{
Molecular Epidemiology and Virulence Characteristics of Klebsiella pneumoniae Strains Isolated from Hospital-Associated Infections
}

\author{
Maria Damian ${ }^{*}, 1$, Codruta-Romanita Usein ${ }^{1}$, Andi-Marian Palade ${ }^{1}$, Stefania Ceciu $^{2}$ and \\ Maria Cosman ${ }^{2}$
}

\author{
${ }^{I}$ Molecular Microbiology Laboratory, ${ }^{2}$ Bacterial Digestive Infections Laboratory, National Institute of Research- \\ Development for Microbiology and Immunology Cantacuzino, Bucharest, Romania
}

\begin{abstract}
Purpose: The present study aimed to confirm by classical and molecular laboratory methods hospitalassociated outbreaks due to virulent Klebsiella pneumoniae strains.

Methods: Eighty three Klebsiella pneumoniae strains isolated from new-born patients, adults and hospital environment and devices in five hospital units, were analyzed for resistance to antibiotics, including last generation cephalosporins, sensitivity to bacteriophages and pulsed-field gel electrophoresis profiles in order to evaluate the epidemiological relatedness and their clonal spreading. Polymerase chain reaction targeting fur genes and several subtractive sequences (SL 002, SL 003, SL 019, SL 020, SL 021 and SL 025) was used for virulence assessment.

Results: More than $50 \%$ of strains were resistant to third generation cephalosporins and among them $69 \%$ were extended spectrum beta-lactamase producers. Phage typing associated with pulse field gel electrophoresis documented the clonal dispersion of strains. Studying the distribution of virulence sequence, our results reveal that fur gene is present in all strains and among the subtractive sequences the most frequent is SL 020 followed by SL 019. None of the analyzed sequences are present in all clinical isolates and none of the bacterial strains carry all these sequences pointing out the heterogeneity of Klebsiella pneumoniae population.

Conclusions: Phage typing method associated with pulse field gel electrophoresis typing and genetic profile for virulence indicated the occurrence of hospital associated-infections produced by Klebsiella pneumoniae strains. Moreover, the results reveal that virulence pattern could be used as a molecular marker in order to define strains which are involved in the process of the development of infectious diseases.
\end{abstract}

Keywords: Klebsiella pneumoniae infections, molecular characterization, PFGE, virulence genes, PCR.

\section{INTRODUCTION}

The genus Klebsiella is grouping Gram-negative opportunistic pathogens frequently isolated from bacteraemia, pneumonia, urinary tract and soft tissue infections.

Immunocompromised individuals suffering from severe diseases such as diabetes mellitus and/or chronic alcoholism, and patients with chronic cardiac diseases, pulmonary obstruction, older persons and new-born babies are the most susceptible hosts. Most of Klebsiella infections are hospital associated, with a high fatality rate if incorrectly treated. Klebsiella is the second cause of nosocomial bacteraemia and lethal sepsis in pediatric ward, especially in premature infants and intensive care units and often causes neonatal sepsis.

Murine models were used to determine host-pathogen interactions during Klebsiella infections, to understand the host response following infection, to detect the bacterial virulence factors which are playing an important role in the

\footnotetext{
*Address correspondence to this author at the Molecular Microbiology Laboratory, National Institute of Research-Development for Microbiology and Immunology Cantacuzino, Splaiul Independentei 103, 050096, Bucharest, Romania; Tel: +4021-5287276; Fax: +4021-5287305;

E-mail: mdamian@cantacuzino.ro
}

severity of infection and to identify a valuable vaccine candidate [1].

Klebsiella pneumoniae strains exhibit different virulence factors such as capsular polysaccharides, type 1 and type 3 adhesins, KPF-28 fimbriae, non fimbrial adhesins CF29K, factors involved in aggregative adhesions and siderophores [2-9]. Comparative studies were carried out to detect the correlation between different capsular serotype, mucoid or non-mucoid phenotype, and the presence of different genetic structures coding for virulence factors or harbored exclusively by virulent strains [10-12]. PCR-based subtractive hybridization technique was used to detect genetic sequences carried only by highly-virulent strains of K2 serotype of Klebsiella pneumoniae, and plasmid DNA analysis, amplified fragment length polymorphism (AFLP) pulsed-field gel electrophoresis (PFGE), restriction of the amplified capsular antigen gene cluster and multi locus sequence typing (http://www.mlst.net/) were used as molecular techniques to discriminate between strains [13$15]$.

During 2003 and the beginning of 2004 an important number of infections due to the Klebsiella pneumoniae strains, some of them leading to lethal sepsis, occurred in some pediatric and/or neonatal hospital units from SouthEastern region of Romania. The aim of the present study 
Table 1. Origin of Klebsiella pneumoniae Strains Included in Study

\begin{tabular}{|c|c|c|c|c|c|c|}
\hline Hospital of Isolation & Lot Definition & Date of Isolation (M/Y) & New-Born Babies & Adults & Hospital Environment & No of Strains \\
\hline \hline H1 & H1-1 & $06 / 2003$ & 6 & 1 & 1 & 8 \\
\hline H2 & H1-2 & $12 / 2003-02 / 2004$ & 27 & 11 & 4 \\
\hline H2-1 & $05-07 / 2004$ & 10 & 6 & 0 \\
\hline H3 & H2-2 & $11 / 2003$ & 4 & 0 & 0 \\
\hline H4 & H4 & $01-07 / 2004$ & 5 & 1 & 0 \\
\hline H5 & H5 & $07-10 / 2004$ & 2 & 4 & 0 & 0 \\
\hline Total of strains & & & 55 & 23 & 5 \\
\hline
\end{tabular}

consists in 1) evaluating the virulence potential of Klebsiella isolates, 2) searching a correlation between the source of isolation and the genetic profiles of strains and 3) assessing the clonal spreading of strains when a hospital-associated infection was suspected.

\section{MATERIAL AND METHODOLOGY}

\section{Bacterial Strains}

A total number of 83 Klebsiella pneumoniae clinical strains isolated from hospitalized new-born patients (55 strains), adults represented by accompanying mothers and/or medical care personnel (23 strains) and from hospital environment and devices in five hospital units (5 strains), were analyzed in this study (Table 1). Strains isolated from hospitals designated H1 $(n=50)$ and H2 $(n=20)$ were suspected as hospital associated. According to the date of isolation, these strains were subdivided in lots H1-1, H1-2 and $\mathrm{H} 2-1, \mathrm{H} 2-2$, respectively. Of all strains, 31 originated from blood culture and the rest from faeces ( 7 strains), amniotic liquid (7 strains), respiratory tract infections (6 strains), ocular swabs (5 strains), skin swabs (6 strains), urine (5 strains), other biological samples (11 strains) and surfaces of hospital devices in contact with new-born babies (5 strains).

The strains isolated from hospitals designated as H3, H4 and H5 were included in this study as controls, for comparison purposes.

The data were presented as absolute number (n), and/or relative frequencies $(\%)$.

Strains were identified by cultural methods as Klebsiella pneumoniae in the clinical laboratories of the hospitals where they originated and were sent to the Reference Laboratory for further characterization.

\section{Susceptibility Testing}

The susceptibility to 12 antibiotics (Table 2) was detected by standard diffusion method, according to the Clinical and Laboratory Standards Institute (CLSI) protocol [16] using Mueller Hinton Agar and Oxoid discs. Double disc synergy test was used for detecting the capacity of bacteria to produce extended spectrum beta-lactamases (ESBLs). The results were recorded as resistant, intermediate and susceptible using the CLSI interpretative criteria and the pattern of resistance was reported as resistotype.
Table 2. List of Antibiotics Used for Susceptibility Testing

\begin{tabular}{|l|c|c|}
\hline \multicolumn{1}{|c|}{ Antibiotic } & Abbreviation & Concentration/Disc \\
\hline \hline Amoxicillin+ clavulanic acid & AMC & $20+10 \mu \mathrm{g}$ \\
\hline Imipenem & IPM & $10 \mu \mathrm{g}$ \\
\hline Ceftazidime & CAZ & $30 \mu \mathrm{g}$ \\
\hline Cefotaxime & CTX & $30 \mu \mathrm{g}$ \\
\hline Cefaclor & CEC & $30 \mu \mathrm{g}$ \\
\hline Amikacin & AK & $30 \mu \mathrm{g}$ \\
\hline Gentamicin & CN & $10 \mu \mathrm{g}$ \\
\hline Tobramicin & TOB & $10 \mu \mathrm{g}$ \\
\hline Chloramphenicol & C & $30 \mu \mathrm{g}$ \\
\hline Nalidixic acid & NA & $30 \mu \mathrm{g}$ \\
\hline Ciprofloxacin & CIP & $5 \mu \mathrm{g}$ \\
\hline Ofloxacin & OFX & $5 \mu \mathrm{g}$ \\
\hline
\end{tabular}

\section{Bacteriophage Typing}

A regional bacteriophage scheme [17] and a Romanian additional one [18] were used to identify the phage type of strains included in this study. The tests were performed with phages at routine testing dilution (RTD) and 100X RTD on nutrient agar (DIFCO) using a 1 hour broth culture. After 4 hours of incubation at $37^{\circ} \mathrm{C}$, the results were recorded as confluent lysis (CL), semi-confluent lysis (SCL), and/or number of phage units and reported as phage type and/or non typable strains.

\section{DNA Amplification}

PCR was performed on crude lysate obtained from an overnight broth culture. Based on the published sequence of different subtractive genomic regions identified to be present only in virulent strains [19], primers were designed and amplicons were named SL002, SL003, SL019, SL020, S1021 and SL025 (Table 3). Ferric uptake regulation gene (fur) was also targeted using a pair of primers designed according to the published sequence [20].

The reactions were performed in a volume of $50 \mu \mathrm{l}$ containing $200 \mu \mathrm{M}$ dNTP mix, 30 pmol of each primer, and $1.5 \mathrm{U}$ of Taq polymerase. Amplifications were performed in a 
Table 3. Primers Used in PCR to Detect the Virulence Profiles of Klebsiella pneumoniae Strains

\begin{tabular}{|c|c|c|c|c|c|}
\hline Sequence Targeted & Access Number & Reference & Primers & Nucleotide Position & Author \\
\hline fur & L23871 & Achenbach, LA et al & $\begin{array}{l}\text { 5'-tagcaacaggacagattccg-3', } \\
\text { 5'-tattttccaccgcgtcgtg-3' }\end{array}$ & $\begin{array}{l}400-419 \\
852-871\end{array}$ & This study \\
\hline SL 002 & AJ 276464 & Lai, YC et al & $\begin{array}{l}\text { 5'-ctggacgatggataacgactc-3', } \\
\text { 5'-acagaacctcatcacattgtcc-3', }\end{array}$ & $\begin{array}{c}3-23 \\
423-444\end{array}$ & This study \\
\hline SL 003 & AJ 276465 & Lai, YC et al & $\begin{array}{l}\text { 5'-taaggagttttatggtgctgac-3, } \\
\text { 5'-tcactcctgaggttatgtatc-3', }\end{array}$ & $\begin{array}{c}9-30 \\
429-449\end{array}$ & This study \\
\hline SL019 & AJ 276851 & Lai, YC et al & $\begin{array}{c}5 \text { '-acgttacctgagcggtgttg-3', } \\
5^{\prime} \text {-ccgcagataaaaaacaagcga-3, }\end{array}$ & $\begin{array}{c}2-21 \\
422-443\end{array}$ & This study \\
\hline SL020 & AJ 276852 & Lai, YC et al & $\begin{array}{c}5 ' \text { '-acctcgattcctgctctgaca-3', } \\
5 \text { '-agaaggtgaaggcgatttaagc-3' }\end{array}$ & $\begin{array}{c}1-22 \\
410-431\end{array}$ & This study \\
\hline SL 021 & AJ 276853 & Lai, YC et al & $\begin{array}{l}5 \text { '-tgcaacctgcatcagttgaag-3', } \\
5 \text { '-tcatgcaaccaaaagtgctcg-3', }\end{array}$ & $\begin{array}{c}03-23 \\
338-358\end{array}$ & This study \\
\hline SL 025 & AJ 276854 & Lai, YC et al & $\begin{array}{c}\text { 5'-cctgctgctatcttaagctc-3, } \\
\text { 5'-agggatctactgatacatacc-3, }\end{array}$ & $\begin{array}{c}9-28 \\
430-450\end{array}$ & This study \\
\hline
\end{tabular}

My Cycler machine (Bio-Rad Laboratories, Hercules, CA, USA) in the following conditions: $4 \mathrm{~min}$ at $94^{\circ} \mathrm{C}$ for initial denaturation followed by 30 cycles of $1 \mathrm{~min}$ at $94^{\circ} \mathrm{C}, 30 \mathrm{sec}$ at $55^{\circ} \mathrm{C}$ for $f u r$, SL 003 and SL $025,57^{\circ} \mathrm{C}$ for SL 019 and SL 021 , and $59^{\circ} \mathrm{C}$ for SL 003 and SL $020,1 \mathrm{~min}$ at $72^{\circ} \mathrm{C}$. A termination cycle of $5 \mathrm{~min}$ at $72{ }^{\circ} \mathrm{C}$ was performed for each PCR.

The amplification products were electrophoresed on $2 \%$ (W/V) agarose (Certified Molecular Biology Agarose, Bio$\mathrm{Rad}$ ) in TBE $1 \mathrm{X}$ using $100 \mathrm{bp}$ as molecular marker.

\section{Molecular Typing}

Pulse field gel electrophoresis (PFGE) was performed according to the standard protocol designed by Centre for Disease Control and Prevention Atlanta, and recommended within the PulseNet EUROPE Project, for Enterobacteria. The XbaI-restricted chromosomal DNA fragments were resolved in a $1 \%$ SeaKem Gold Agarose (Lonza Group Ltd. Switzerland) using a CHEF-Mapper system (Bio-Rad). For each gel the well-characterized strain Salmonella Braenderup H9812 was included as both procedure control and molecular size marker.

The electrophoretic conditions used were as follows: initial switch time, $2.16 \mathrm{~s}$, final switch time $54.17 \mathrm{~s}$, run time $20 \mathrm{~h}$, angle $120^{\circ}$, gradient $6.0 \mathrm{~V} / \mathrm{cm}$, temperature $14^{\circ} \mathrm{C}$, and ramping factor linear. The gel image, acquired by a CCD camera (Vilber Lourmat dark room) was analyzed using Dice similarity coefficient, UPGMA (unweighted pair group arithmetic average) algorithm and FingerPrinting II software (BioRad).

\section{RESULTS}

\section{The Susceptibility to the Antibiotics Versus the Origin of Strains}

A set of 12 antibiotics usually prescribed for Klebsiella infections was used to detect the presence of resistant/multiresistant strains circulating in hospitals and suspected to be at the origin of hospital associated infections. A total of 17 patterns of resistance were identified among all the 83 strains analyzed (Table 4 ).
The patterns were denominated as R1-R16 and S, the last one comprising the strains susceptible to all the 12 antibiotics used. The types R1-R4 and R6-R8 were represented by strains resistant to the third generation cephalosporins. Pattern R2 was the most prevalent, 35 strains presenting this profile of resistance, and 28 of them being isolated from new-born babies. A number of 17 strains were susceptible to all antibiotics tested, 12 being isolated from adults. The other patterns were represented by fewer strains and were isolated from babies, adults and/or hospital environment. A number of 5 profiles of resistance were identified among the H1-1 strains (Fig. 1A), R2 being represented by 3 strains, two of them isolated from new-born babies and one from a device associated to the babies care. When we analyzed the strains H1-2 (Fig. 1B), we found that 26 of 42 strains showed the R2 type. The R2 type was also prevalent within the lot $\mathrm{H} 3$ of strains (Fig. 2A).

The four strains isolated from blood specimens of babies, included in the lot $\mathrm{H} 2-2$, were susceptible to the all antibiotics used (Fig. 3B), but the strains H2-1 were distributed among 7 patterns of resistance, only 2 of them being resistant to cephalosporins of third generation (Fig. 3A).

When the double disc test was performed, a number of 29 strains were detected as ESBL producers. R2 type of resistance was displayed by 24 ESBL positive strains, and the rest were distributed between 4 resistotypes $(\mathrm{R} 1=1$, $\mathrm{R} 3=2, \mathrm{R} 6=1$ and $\mathrm{R} 7=1$ ). A number of $21 \mathrm{ESBL}$ positive strains were isolated in unit H1 while no strain was ESBL positive in unit H2 (Table 5).

\section{Association Between Phage Type and Origin of Strains}

By using the two schemes of phage typing of Klebsiella pneumoniae strains a correlation between phage type and the involvement of strains in nosocomial infection was detected. The 8 strains of lot H1-1 presented different profiles of sensitivity to the specific phages, being dispersed among types IIA1, IIA2 and non-typable strains. Within the same hospital unit, strains isolated later from new-born babies and designated as lot H1-2, were all identified as IB1 phage type, while those isolated from adults were identified as different 
Table 4. Resistotypes Identified Among the Klebsiella pneumoniae Strains

\begin{tabular}{|c|c|c|c|c|}
\hline No. of Resistotypes & Denomination & Pattern of Resistance & No. of Strains & $\%$ \\
\hline 1 & $\mathrm{R} 1$ & AMC, CAZ, CTX, CEC, CN, TOB, C, NA & 1 & 1.21 \\
\hline 2 & $\mathrm{R} 2$ & AMC, CAZ, CTX, CEC, CN, TOB, C & 35 & 42.17 \\
\hline 3 & $\mathrm{R} 3$ & AMC, CAZ, CTX, CRO, CEC, CN, TOB & 1 & 1.21 \\
\hline 4 & R4 & $\mathrm{AMC}, \mathrm{CAZ}, \mathrm{CTX}, \mathrm{CEC}, \mathrm{CN}, \mathrm{TOB}$ & 2 & 2.40 \\
\hline 5 & R5 & $\mathrm{CN}, \mathrm{TOB}, \mathrm{C}, \mathrm{NA}, \mathrm{CIP}, \mathrm{OFX}$ & 1 & 1.21 \\
\hline 6 & R6 & $\mathrm{AMC}, \mathrm{CAZ}, \mathrm{CTX}, \mathrm{CEC}, \mathrm{CN}$ & 2 & 2.40 \\
\hline 7 & R7 & AMC, CAZ, CTX, CEC, C & 1 & 1.21 \\
\hline 8 & $\mathrm{R} 8$ & $\mathrm{AMC}, \mathrm{CAZ}, \mathrm{CTX}, \mathrm{CEC}$ & 1 & 1.21 \\
\hline 9 & R9 & $\mathrm{AMC}, \mathrm{CN}, \mathrm{TOB}, \mathrm{C}$ & 3 & 3.61 \\
\hline 10 & R10 & $\mathrm{AMC}, \mathrm{C}, \mathrm{NA}$ & 1 & 1.21 \\
\hline 11 & R11 & $\mathrm{AMC}, \mathrm{CN}, \mathrm{TOB}$ & 7 & 8.43 \\
\hline 12 & $\mathrm{R} 12$ & $\mathrm{CN}, \mathrm{TOB}, \mathrm{C}$ & 3 & 3.61 \\
\hline 13 & $\mathrm{R} 13$ & $\mathrm{AMC}, \mathrm{CN}$ & 4 & 4.82 \\
\hline 14 & R14 & $\mathrm{C}, \mathrm{NA}$ & 1 & 1.21 \\
\hline 15 & R15 & TOB, C & 1 & 1.21 \\
\hline 16 & R16 & $\mathrm{AMC}$ & 2 & 2.40 \\
\hline 17 & $\mathrm{~S}$ & Susceptible to all 12 antibiotics & 17 & 20.48 \\
\hline Total & & & 83 & 100 \\
\hline
\end{tabular}

phage types. Strains isolated from surfaces of devices associated with the ambient of new-born babies were also identified as IB1 phage type. All the strains isolated from new-born babies in hospital 2, designated as lot $\mathrm{H} 2-1$, were identified to be IA1 phage type while the strains isolated from accompanying mothers or hospital care personnel belonged to other phage types. Strains belonging to the lot H2-2 were all non-typable. Strains grouped in the control lots (H3, H4 and H5) showed various profiles of susceptibility to the bacteriophages.

\section{Clonal Analysis}

After $X b a I$ restriction of genomic DNA and fragments separation by PFGE, the strains H1-1 showed great divergence, the genetic distance between them being up to $50 \%$. Three strains, two from new-born babies and one from an environmental device associated to the babies care seemed to be clonal (Fig. 1A).

All the strains H1-2 also showed up to $44 \%$ divergence, but the strains isolated from new-born babies and their environment were closely related compared with the strains isolated from accompanying mothers and hospital care personnel (Fig. 1B).

The analysis of the strains $\mathrm{H} 2-1$ revealed that strains from children were closely related ( $97 \%$ identity) but isolates from accompanying mothers and hospital care personnel were divergent (Fig. 3A).

As expected, strains from hospital units $\mathrm{H} 3$ and $\mathrm{H} 4$ were unrelated, each strain showing a different PFGE pattern, only two strains in $\mathrm{H} 3$ being identical (Fig. 2).

\section{Genetic Profile Associated to the Strains Virulence}

The PCR screening for the presence of the selected seven genomic regions revealed a number of 13 genetic patterns of amplification, noted from GP1 to GP13 (Table 6).

The most frequent genetic profile was GP1 $(n=54)$ with two amplified regions, SL 020 and SL 019. These two subtractive regions were the most prevalent ones. They were identified in 81 and 74 strains respectively. The pattern GP8 was the second as frequency $(n=10)$ strains included in this group carrying SL 020, SL 019 and SL 003 regions. The region named SL 003 was identified as the third subtractive genetic region as prevalence (19 strains). The genetic region SL 021 was detected only in one strain while gene fur, coding for regulation of ferric uptake, was present in all the analyzed strains.

The isolates originating in H1-1 were all GP1, except the strain isolated from the hospital environment which showed the genetic pattern 3. All the H1-2 strains isolated from newborn babies were included in GP1, while the strains isolated from accompanying personnel, care personnel and hospital environment were distributed among patterns GP1, GP2, GP4, GP5 and GP7. H2-1 strains displayed 7 genetic patterns, but the strains isolated from babies were shared by GP1 and GP8 as the strains H2-2. Isolates from $\mathrm{H} 3$ and $\mathrm{H} 4$ were included in GP1 and GP8 patterns and also in others, less frequently encountered, GP9, GP10, GP13.

\section{DISCUSSION}

Klebsiella is a well known cause of community-acquired bacterial pneumonia, but the great majority of infections are 

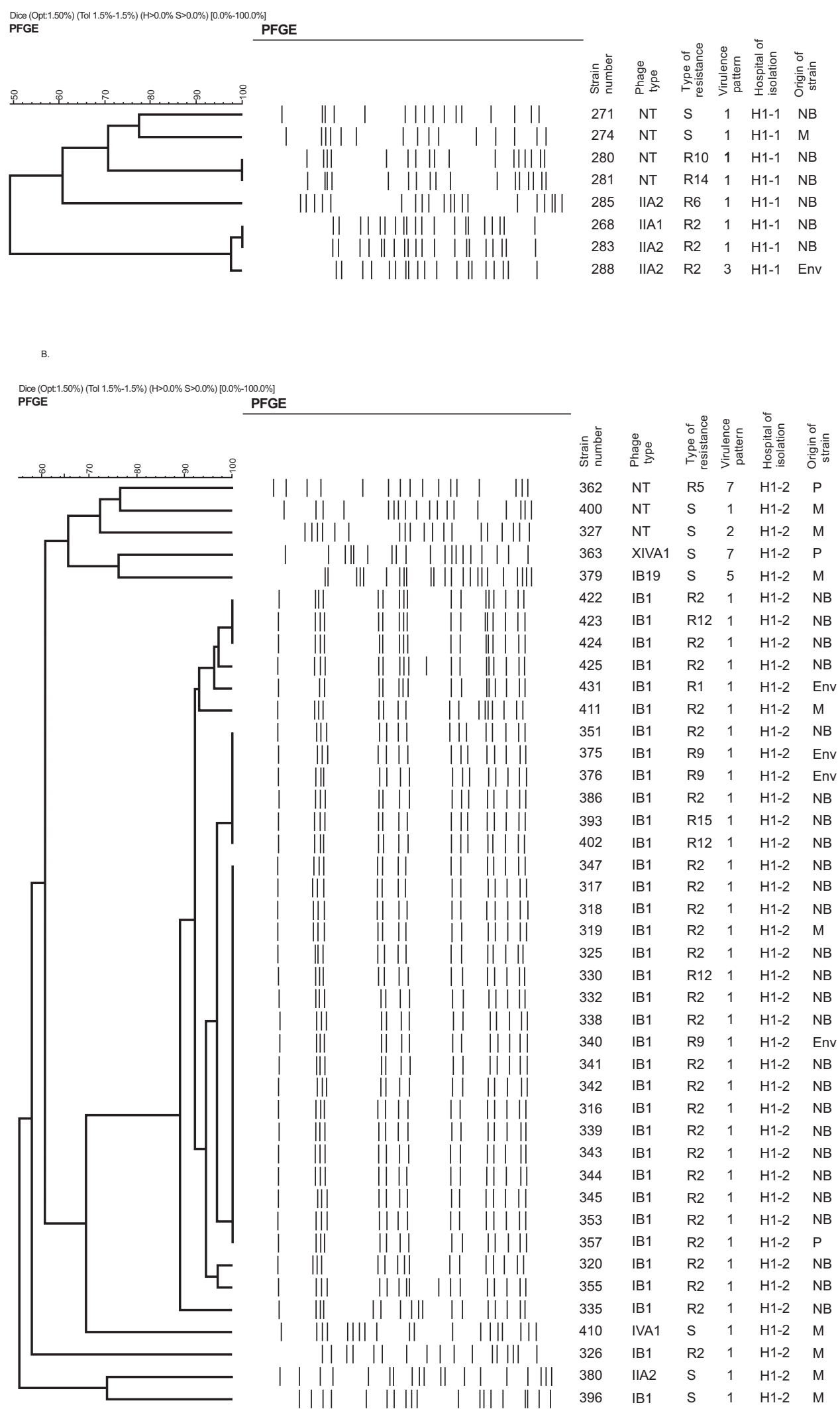

Fig. (1). Molecular and phenotypic characterization of Klebsiella strains isolated from hospital H1. (A) H1-1 lot of strains; (B) H1-2 lot of strains. The restriction profiles were obtained after $X b a \mathrm{I}$ digestion of genomic DNA and separation of fragments by pulsed field gel electrophoresis. Computer analysis was done by using Fingerprinting II software (BioRad Laboratories, Hercules, CA, USA), applying unweighted pair group method with optimization of $1.5 \%$ and tolerance of $1.5 \%$.

NT: non-typable; NB: new-born babies; M: mothers; P: care hospital personnel; Env: environment. 
A.

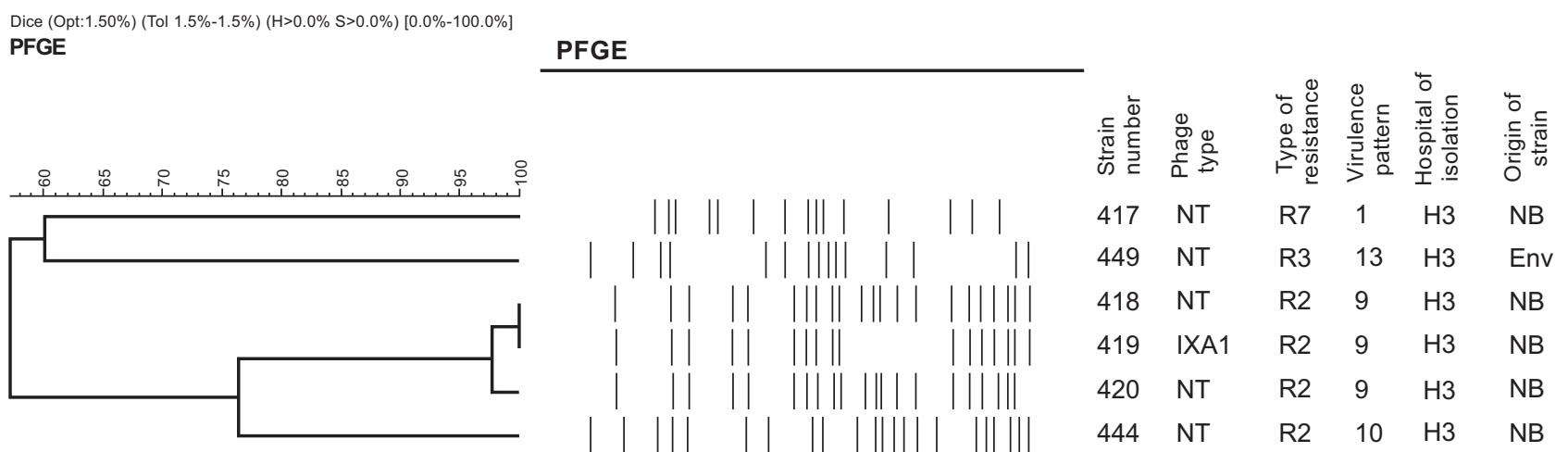

B.

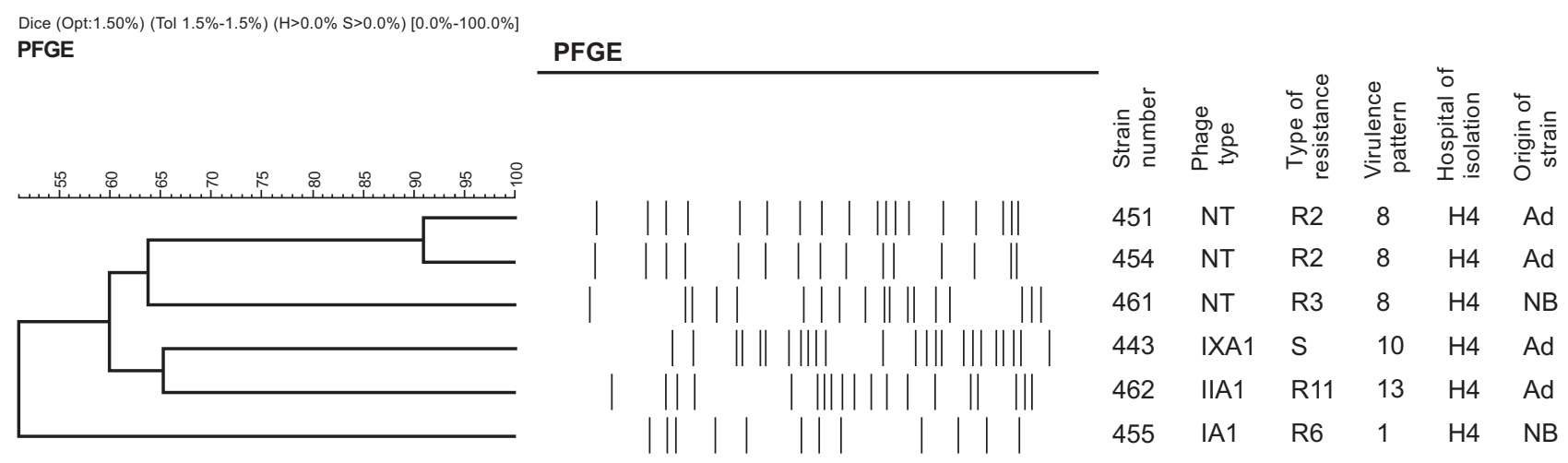

Fig. (2). Characteristics of Klebsiella strains isolated from H3 (A) and H4 (B) hospitals. NT: non-typable; NB: new-born babies; Ad: adults; Env: environment.

hospital-associated. Meningitis and other infections causing septicemia in new born babies hospitalized in intensive care units became a major threat for pediatric wards. The increasing number of Klebsiella strains producing ESBLs leads to limitation of therapeutic options and calls for enhancing surveillance and control measures of hospital acquired infections. Prevalence of ESBL producing Klebsiella pneumoniae strains causing bloodstream infections runs to $97 \%$ in neonatal and pediatric intensive care units in India [21] and to $30 \%$ in Italy [22]. A surveillance study developed in a University Hospital in Turkey reveals a prevalence of $57.1 \%$ Klebsiella pneumoniae ESBL producing strains [23] whereas the general circulation of these strains is of $33-86 \%$. A nationwide survey in Korea aiming to detect the prevalence of ESBL Klebsiella pneumoniae producing strains identified $29 \%$ resistance to ceftazidime and $32 \%$ to cefotaxime [24]. The Health Protection Agency reported 14\% Klebsiella strains resistant to the third generation cephalosporins in 2007 [www.hpa.org.uk] and in other European countries the prevalence ranged between $0.0 \%$ in Iceland and $61.8 \%$ in Greece [www.rivm.nl/earss].

Our study indicates a large circulation of strains resistant to more than three antibiotics. A number of 43 strains
$(51.80 \%)$ were resistant to third generation cephalosporins (patterns of resistance R1, R2, R3, R4, R6, R7 and R8), most of them being isolated from new-born babies while the isolates from accompanying mothers, hospital care personnel and environment associated with the babies were less resistant. A percent of $33.74 \%$ were ESBL producing strains, most of them being isolated in the hospital unit 1 where a hospital-associated infection was reported. We cannot suppose that an epidemic resistant strain was spread within a hospital because different resistance patterns were identified among the strains from the same unit.

Phage typing proved to be a useful method for microbiological surveillance and typing of Klebsiella pneumoniae strains indicated the occurrence of hospital associated-infections in the new-born babies units.

When PFGE was associated, the clonal dispersion of the strains among the new-born babies was documented even if their source was not detected, the strains isolated from accompanying persons, care personnel and devices associated with babies presenting different phage types and/or PFGE profiles. Strains isolated from new-born babies in H1-2 showed the same phage type and were included in the same PFGE cluster. These findings are strongly pleading for a hospital infection. The same situation occurred in 
A.
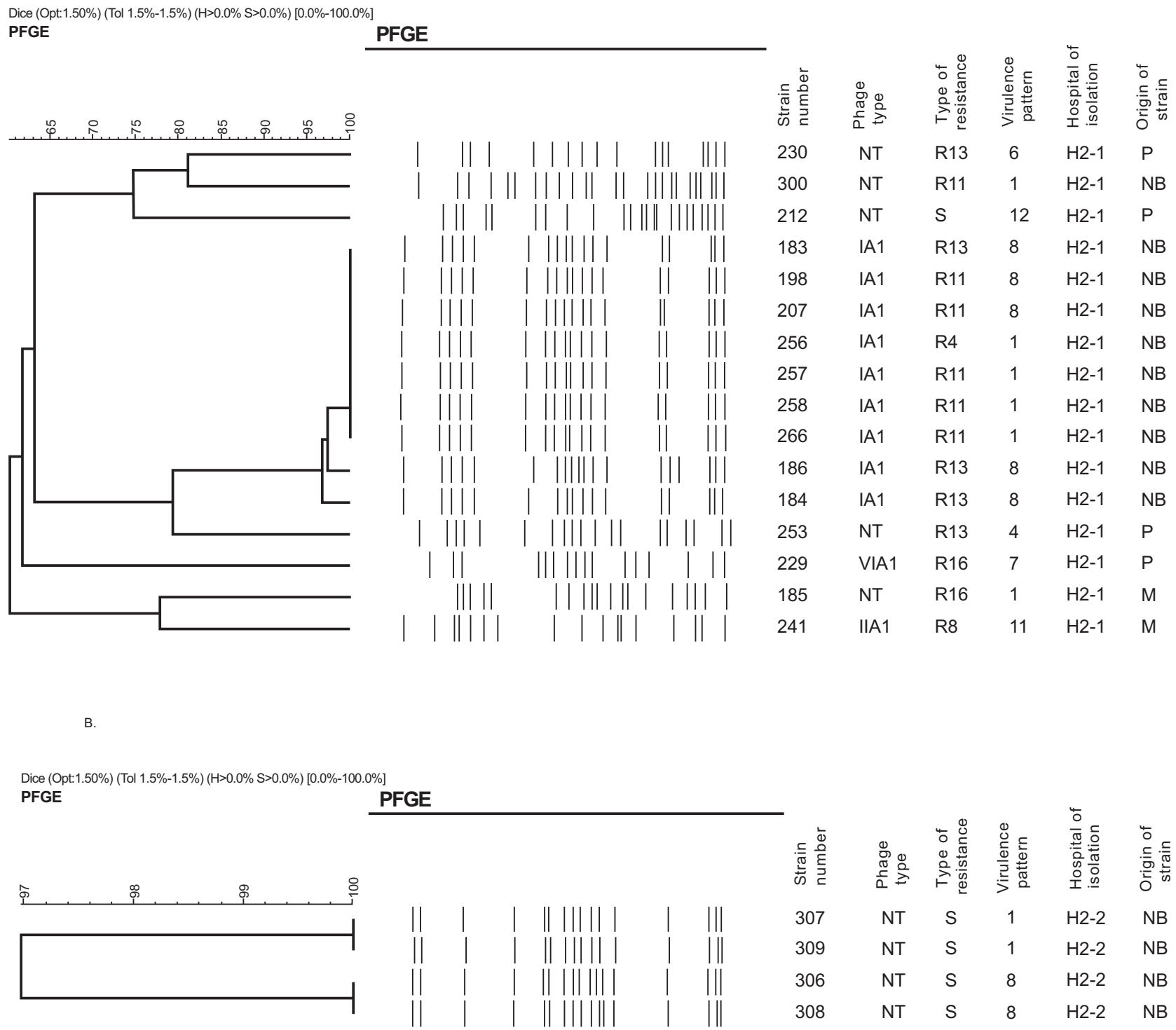

Fig. (3). Dendrogram of PFGE patterns for Klebsiella isolates from H2 hospital. (A) H2-1 lot of strains; (B) H2-2 lot of strains. NT: nontypable; NB: new-born babies; M: mothers; P: care hospital personnel; Env: environment.

hospital unit $\mathrm{H} 2-1$, where the strains isolated from babies showed the same phage type and 97\% PFGE similarity.

Geographic differences in the spectrum of diseases caused by Klebsiella pneumoniae, clonal dispersion and virulence characteristics of strains have been documented, and the correlation between the type of infection, its gravity and sometimes lethality, and the virulence characteristics was analyzed [25, 26]. Capsular type, mucoid phenotype, siderophores production and their regulation, biofilm formation and aggregative adherence to the human intestinal mucous surfaces [27-31] were studied in order to define phenotypic and/or molecular markers which could help the laboratory diagnosis and epidemiology of infections due to these bacteria. Novel virulence genes [32] involved in liver damages and subtractive gene that are present only in virulent strains, were characterized and sequences were deposited in international data banks. Studying the distribution of some of these genes among our strains collection, a correlation was found between our results and those reported by other authors.

The most frequent sequence identified was SL 020 (97.59\%). Only two strains were PCR negative for this sequence, result which can be explained by the fact that these strains were not isolated from infections (one was isolated from hospital environment and the other from the skin of care personnel). The sequence SL 019, the second as incidence in Lai YC et al. study was also the second as incidence in our study $(89,16 \%)$. A correlation between the presence of this sequence and the infection was also observed. The less detected sequences, SL 021 and SL 025, were always associated with SL 020 and SL 019. The Klebsiella pneumoniae strains analyzed in our study showed 
Table 5. Relationship Between Antibiotic Susceptibility and Origin of Strains

\begin{tabular}{|c|c|c|c|c|}
\hline Lot Definition & Origin of Strains & Resistotype & No. of Strains & No. of Strains ESBL Positive \\
\hline \multirow[t]{7}{*}{$\mathrm{H} 1-1$} & \multirow[t]{5}{*}{ New-born babies } & $\mathrm{R} 2$ & 2 & 2 \\
\hline & & S & 1 & \\
\hline & & $\mathrm{R} 10$ & 1 & \\
\hline & & R14 & 1 & \\
\hline & & R6 & 1 & \\
\hline & Adults & $\mathrm{S}$ & 1 & \\
\hline & Hospital environment & R2 & 1 & 1 \\
\hline \multirow[t]{8}{*}{$\mathrm{H} 1-2$} & \multirow[t]{3}{*}{ New-born babies } & R2 & 23 & 17 \\
\hline & & $\mathrm{R} 12$ & 3 & \\
\hline & & R15 & 1 & \\
\hline & \multirow[t]{3}{*}{ Adults } & $\mathrm{S}$ & 8 & \\
\hline & & R2 & 2 & \\
\hline & & R5 & 1 & \\
\hline & \multirow[t]{2}{*}{ Hospital environment } & R9 & 3 & \\
\hline & & R1 & 1 & 1 \\
\hline \multirow[t]{7}{*}{$\mathrm{H} 2-1$} & \multirow[t]{3}{*}{ New-born babies } & R11 & 6 & \\
\hline & & R13 & 3 & \\
\hline & & R4 & 1 & \\
\hline & \multirow[t]{4}{*}{ Adults } & $\mathrm{S}$ & 2 & \\
\hline & & $\mathrm{R} 13$ & 1 & \\
\hline & & R16 & 2 & \\
\hline & & R8 & 1 & \\
\hline $\mathrm{H} 2-2$ & New-born babies & $\mathrm{S}$ & 4 & \\
\hline \multirow[t]{3}{*}{$\mathrm{H} 3$} & \multirow[t]{2}{*}{ New-born babies } & R2 & 4 & 3 \\
\hline & & R7 & 1 & 1 \\
\hline & Hospital environment & R3 & 1 & 1 \\
\hline \multirow[t]{5}{*}{$\mathrm{H} 4$} & \multirow[t]{2}{*}{ New-born babies } & R3 & 1 & 1 \\
\hline & & R6 & 1 & 1 \\
\hline & \multirow[t]{3}{*}{ Adults } & $\mathrm{S}$ & 1 & \\
\hline & & R2 & 2 & \\
\hline & & R11 & 1 & \\
\hline H5 & New-born babies & R2 & 1 & 1 \\
\hline Total & & & 83 & 29 \\
\hline
\end{tabular}

between two $(n=3)$ and five virulence genes $(n=5)$. Our results are in agreement with those suggesting that pathogenic Klebsiella pneumoniae population is highly heterogeneous and that none of the analyzed sequences are present in all clinical isolates and none of bacterial strains carries all these sequences. Most of the strains carrying SL 020 and SL 019 (pattern designated PG1) were isolated from new-born babies and this virulence pattern was correlated with other epidemiological markers (phage type and PFGE type) when the strains were suspected to be hospitalassociated.

\section{CONCLUSION}

Taking in to consideration that Klebsiella spp. is a heterogeneous microorganism, selective and specific methods are necessary to define the strains responsible or not for infections. Phage typing method associated with PFGE typing and genetic profile for virulence indicated the occurrence of hospital associated-infections produced by Klebsiella pneumoniae strains. Moreover, the results reveal that virulence pattern could be used as a molecular marker for differentiating strains involved in infectious processes. 
Table 6. Virulence Pattern of Klebsiella pneumoniae Strains

\begin{tabular}{|c|c|c|c|c|c|c|c|c|}
\hline \multirow{2}{*}{ Pattern Designation } & \multicolumn{7}{|c|}{ Sequences Amplified } & \multirow{2}{*}{ Number of Strains } \\
\hline & fur & SL002 & SL003 & SL019 & SL020 & SL021 & SL025 & \\
\hline GP1 & + & - & - & + & + & - & - & 54 \\
\hline GP2 & + & - & - & + & + & - & + & 1 \\
\hline GP3 & + & - & - & + & - & - & - & 1 \\
\hline GP4 & + & - & - & - & + & - & - & 2 \\
\hline GP5 & + & - & + & - & + & - & - & 3 \\
\hline GP6 & + & - & + & + & - & - & - & 1 \\
\hline GP7 & + & - & + & + & + & - & + & 2 \\
\hline GP8 & + & - & + & + & + & - & - & 10 \\
\hline GP9 & + & + & - & - & + & - & - & 3 \\
\hline GP10 & + & + & - & + & + & - & - & 2 \\
\hline GP11 & + & + & - & + & + & + & - & 1 \\
\hline GP12 & + & + & + & - & + & - & - & 1 \\
\hline GP13 & + & + & + & + & + & - & - & 2 \\
\hline Positive strains & 83 & 9 & 19 & 74 & 81 & 1 & 3 & 83 \\
\hline
\end{tabular}

\section{ACKNOWLEDGEMENTS}

This work was partially supported by research grant from the Romanian Agency for Scientific Research (VIASAN Program, Project number 331/2003), and the National Institute of Research-Development for Microbiology and Immunology Cantacuzino, Bucharest, Romania.

We thank the clinical microbiologists who kindly provided us the Klebsiella pneumoniae isolates.

\section{REFERENCES}

[1] Singh BR, Sharma VD. Potential of Klebsiella pneumoniae cytotoxin toxoid as vaccine against klebsiellosis in rabbits and mice. Vaccine 2001; 19: 4505-10.

[2] Podschun R, Ullmann U. Klebsiella spp. as nosocomial pathogens: epidemiology, taxonomy, typing methods, and pathogenicity factors. Clin Microbiol Rev 1998; 11: 589-603.

[3] Arakawa Y, Wacharotayankun R, Nagatsuka T, Ito H, Kato N, Ohta M. Genomic organization of the Klebsiella pneumoniae cps region responsible for serotype K2 capsular polysaccharide synthesis in virulent strain Chedid. J Bacteriol 1995; 177: 1788-96.

[4] Tomas JM, Benedi VJ, Ciurana B, Jofre J. Role of capsule and O antigen in resistance of Klebsiella pneumoniae to serum bactericidal activity. Infect Immun 1986; 54: 85-9.

[5] Clegg S, Purcell BK, Pruckler J. Characterization of genes encoding type 1 fimbriae of Klebsiella pneumoniae, Salmonella typhimurium, and Serratia marcescens. Infect Immun 1987; 55: 281-7.

[6] Hornick DL, Allen BL, Horn MA, Clegg S. Fimbrial types among respiratory isolates belonging to the family Enterobacteriaceae. J Clin Microbiol 1991; 29: 1795-800

[7] Sebghati TAS, Korhonen TK, Hornick DB, Clegg S. Characterization of the type 3 fimbrial adhesins of Klebsiella strains. Infect Immun 1998; 66: 2887-94.

[8] Gerlach GF, Clegg S, Allen BL. Identification and characterization of the genes encoding the type 3 and type 1 fimbrial adhesins of Klebsiella pneumoniae. J Clin Microbiol 1989; 171: 1262-70.

[9] Martino PD, Bertin Y, Girardeau JP, Livrelli V, Joly B, DarfeuilleMichaud A. Molecular characterization and adhesive properties of CF29K, and adhesion of Klebsiella pneumoniae strains involved in nosocomial infections. Infect Immun 1995; 63: 4336-44.
[10] Darfeuille-Michaud A, Jallat C, Aubel D, et al. R-plasmid-encoded adhesive factor in Klebsiella pneumoniae strains responsible for human nosocomial infections. Infect Immun 1992; 60: 44-55.

[11] Favre-Bonte S, Darfeuille-Michaud A, Forestier C. Aggregative adherence of Klebsiella pneumoniae to human intestine-407 cells. Infect Immun 1995; 63: 1318-28.

[12] Lau HY, Clegg S, Moore TA. Identification of Klebsiella pneumoniae genes uniquely expressed in a strain virulent using a murine model of bacterial pneumonia. Microb Pathog 2007; 42: 148-55.

[13] Damian M, Cosman M, Negut M. Plasmid DNA analysis in epidemiological studies of infections by Klebsiella pneumoniae. Rom Arch Microbiol Immunol 1994; 53: 81-8.

[14] Jonas D, Spitzmuller B, Daschner FD, Verhoef J, Brisse S. Discrimination of Klebsiella pneumoniae and Klebsiella oxytoca phylogenetic groups and other Klebsiella species by use of amplified fragment length polymorphism. Res Microbiol 2004; 155: 17-23.

[15] Brisse S, Issenhuth-Jeanjean S, Grimont PAD. Molecular serotyping of Klebsiella species isolates by restriction of amplified capsular antigen gene cluster. J Clin Microbiol 2004; 42: 3388-98.

[16] Clinical and Laboratory Standards Institute. Performance standards for antimicrobial disk susceptibility tests. Approved standard. 9th ed. Document M2-A9. Wayne (PA), The Institute 2006.

[17] Slopek S, Hessek AP, Milch H, Deak S. A working scheme for bacteriophage typing of Klebsiella bacilli. Arch Immun Ther Exp 1967; 15: 589-93.

[18] Popovici M, Cosman M, Olinescu E. The additional phages for Klebsiella used in phage typing. Bacteriol Virusol Parazitol Epidemiol 1978; 23: 85-9.

[19] Lai YC, Yang SL, Peng HL, Chang HY. Identification of genes present specifically in a virulent strain of Klebsiella pneumoniae. Infect Immun 2000; 68: 7149-51.

[20] Achenbach LA, Yang W. The fur gene from Klebsiella pneumoniae: characterization, genomic organization and phylogenetic analysis. Gene 1997; 185: 201-7.

[21] Harish BN, Menezes GA, Shekatkar S, Parija SC. Extendedspectrum $\beta$-lactamase producing Klebsiella pneumoniae from blood culture. J Med Microbiol 2007; 56: 999-1000.

[22] Tumbarello M, Spanu T, Sanguinetti M, et al. Bloodstrean infections caused by extended-spectrum- $\beta$-lactamase-producing Klebsiella pneumoniae: risk factors, molecular epidemiology, and clinical outcome. Antimicrob Agents Chemother 2006; 50: 498504. 
[23] Tasli H, Bahar H. Molecular characterization of TEM- and SHVderived extended-spectrum beta-lactamases in hospital-based Enterobacteriaceae in Turkey. Jpn J Infect Dis 2005; 58: 162-7.

[24] Jeong SH, Bae IK, Lee JH, et al. Molecular characterization of extended-spectrum beta-lactamases produced by clinical isolates of Klebsiella pneumoniae and Escherichia coli from Korean nationwide survey. J Clin Microbiol 2004; 42: 2902-6.

[25] Yu VL, Hansen DS, Ko WC, et al. Virulence characteristics of Klebsiella and clinical manifestations of $K$. pneumoniae bloodstream infections. Emerg Infect Dis 2007; 13: 986-93.

[26] Struve C, Krogfelt KA. Role of capsule in Klebsiella pneumoniae virulence: lack of correlation between in vitro and in vivo studies. FEMS Microbiol Lett 2003; 218: 149-54.

[27] Simoons-Smit AM, Verweij-Van VAMJJ, Maclaren DM. The role of $\mathrm{K}$ antigens as virulence factors in Klebsiella. J Med Microbiol $1986 ; 21: 133-7$
[28] Yeh KM, Kurup A, Siu LK, et al. Capsular serotype K1 or K2, rather than magA and $r m p \mathrm{~A}$, is a major virulence determinant for Klebsiella pneumoniae liver abscess in Singapore and Taiwan. J Clin Microbiol 2007; 45: 466-71.

[29] Neilands JB. Siderophores: structure and function of microbial iron transport compounds. J Biol Chem 1995; 270: 26723-6.

[30] Lavender HF, Jagnow JR, Clegg S. Biofilm formation in vitro and virulence in vivo of mutants of Klebsiella pneumoniae. Infect Immun 2004; 72: 4888-90.

[31] Langstraat J, Bohse M, Clegg S. Type 3 fimbrial shaft (MrkA) of Klebsiella pneumoniae, but not the fimbrial adhesin (MrkD), facilitates biofilm formation. Infect Immun 2001; 69: 5805-12.

[32] Fang CT, Chuang YP, Shun CT, Chang SC, Wang JT. A novel virulence gene in Klebsiella pneumoniae strains causing primary liver abscess and septic metastatic complications. J Exp Med 2004; 199: 697-705.

Received: February 18, 2009

Revised: August 9, 2009

Accepted: August 10, 2009

(C) Damian et al.; Licensee Bentham Open.

This is an open access article licensed under the terms of the Creative Commons Attribution Non-Commercial License (http://creativecommons.org/licenses/by$\mathrm{nc} / 3.0 /$ ) which permits unrestricted, non-commercial use, distribution and reproduction in any medium, provided the work is properly cited. 